\title{
Voltage Control Of Three Phase Ac/Dc Pwm Converters Using Feedback Linearisation
}

\author{
Ancha.Sadhana ${ }^{1}$, K. Bhavana ${ }^{2}$ \\ ${ }^{I}$ M.Tech Student Scholar, Department of Electrical \& Electronics Engineering, P.V.P Siddhartha Institute Of \\ Technology, Vijayawada, A,P, India \\ ${ }^{2}$ Assistant professor, Department of Electrical \& Electronics Engineering, P.V.P Siddhartha Institute Of \\ Technology, Vijayawada, A,P, India
}

\begin{abstract}
This paper proposes a voltage control strategy for a three level PWM converter based on feedback linearization in order to control dc bus voltage. Incorporating the power balance of the input and output sides in system modeling, a nonlinear model of the PWM converter is derived with state variables such as ac input currents and dc output voltage. Feedback linearization transforms a nonlinear system into a linear system. Then by input-output feedback linearization, the system is linearized and a state feedback control law is obtained by pole placement. For robust control to parameter variations, integrators are added to the exact feedback control law. Since the fast voltage control is feasible for load changes, it is shown that the capacitor size can be reduced remarkably. The input current is regulated to be sinusoidal and the source power factor can be controlled at unity. This feedback linearization technique can be extended for permanent magnet synchronous generator wind power system at the grid voltage sag. The proposed method is tested and the results of simulation are observed using MATLAB/SIMULINK.
\end{abstract}

Keywords: AC/DC pulse width modulation converter, DC-link voltage, feedback linearization, permanent magnet synchronous generator (PMSG), wind power, matlab/simulink.

\section{Introduction}

In this paper, simulation of dc machine speed control which is fed by three - phase voltage source rectifier under input - output linearization nonlinear control, is realized. The speed Control loop is combined with input-output linearization nonlinear control. By means of the simulation, power factor, line currents, harmonic distortions and dc machine speed are presented.

In nature, most of the systems are nonlinear. But, most of them are thought as linear and the control structures are realized with linear approach. Because, linear control methods are so strong to define the stability of the systems. However, linear control gives poor results in large operation range and the effects of hard nonlinearities cannot be derived from linear methods. Furthermore, designing linear controller, there must not be uncertainties on the parameters of system model because this causes performance degradation or instability. For that reasons, the nonlinear control are chosen. Nonlinear control methods also provide simplicity of the controller.

Considering a three phase supply for every voltage source there will be some impedance drop, after measuring for rectification process to eliminate third and fifth harmonics we use six pulse bridge converters, after rectification this gets stored in capacitor, this is called DC link voltage. To control DC link voltage in this paper we used insulated gate bipolar transistor (IGBT'S) other than SCR because it has high holding capability compared to SCR'S. IGBT'S reduce the low harmonics depending on pulse width modulation (PWM) technique it generates gate pulses. PWM technique is nothing but decreasing width of pulse. To reduce the switching losses we go for SVPWM i.e. in IGBT parameters we consider voltage and current feedback and their magnitude is derived and the magnitude is converted into polar form, this technique is called parks transformation technique.

Feedback linearization transforms a non-linear system into a linear one, then by input output feedback linearization the system is linearized and a state feedback control law is obtained by pole placement. Since the fast voltage control is feasible for load changes, it is shown that the capacitor size can be reduced remarkably. The input current is regulated to be sinusoidal and the source power factor can be controlled at unity. This can be extended by permanent magnet synchronous generator connected wind power system to maintain the voltage constant when the total system is connected generator side as well as grid side with the help of dc capacitor. 


\section{Feedback Linearization Technique}

Feedback linearization can be used as a nonlinear design methodology. The basic idea is first to transform a nonlinear system into a (fully or partially) linear system, and then to use the well-known and powerful linear design techniques to complete the control design. It is completely different from conventional linearization

In feedback linearization, instead of linear approximations of the dynamics, the process is carried out by exact state transformation and feedback. Besides, it is thought that the original system is transformed into an equivalent simpler form. Of the different types of linearization we use only input and output feedback linearization.

\subsection{Input-Output Feedback Linearization Technique}

Furthermore, there are two feedback linearization methods that are

1)input-state feedback linearizationand

2) input-output feedback linearization

The input-output feedback linearization technique is summarized by three rules;

$\square$ Deriving output until input appears

$\square$ choosing a new control variable which provides to reduce the tracking error and to eliminate the nonlinearity

$\square$ Studying stability of the internal dynamics which are the part of system dynamics cannot be observed in input-output linearization.

If it is considered an input-output system,

Before applying the nonlinear control to the PWM converter,

a feedback linearization theory for multivariable systems is described,

Consider a multi-input multi-output (MIMO) system as follows:

Input -output feedback linearisation

$\dot{x}=\mathrm{f}(\mathrm{x})+\mathrm{g}(\mathrm{x}) \mathrm{u}----1$

$\mathrm{Y}=\mathrm{h}(\mathrm{x})$

Where

$\mathrm{x}$ state vector;

u control inputs;

y outputs;

f, g smooth vector fields;

$\mathrm{h}$ smooth scalar function.

$\dot{y}=\frac{d h}{d x}[f(x)+g(x) u---3$

An approach to obtain the input-output linearization of the

MIMO system is to differentiate the output $y$ of the system until the inputs appear. By differentiating

Output must be differentiated till inputs $\mathrm{u}$ appears

$=L_{f} \mathrm{~h}(\mathrm{x})+L_{g} \mathrm{~h}(\mathrm{x}) \mathrm{u}---4$

$L_{f} h$ and $L_{g}$ hare lie derivatives of $\mathrm{f}(\mathrm{x})$ and $\mathrm{h}(\mathrm{x})$

$L_{f} \mathrm{~h}(\mathrm{x})=\frac{d h}{d x} \mathrm{f}(\mathrm{x})----5$

$L_{g} h(x)=\frac{d h}{d x} g(x)---6$

If $\mathrm{k}$ is taken as constant order derivative of $\mathrm{h}(\mathrm{x})$ and zero

$L_{f}^{k} h(x)=L_{f} L_{f}^{k-1} h(x)---7$

$=\frac{d\left(L_{f}^{k-1} h\right)}{d x} f(x)----8$

$L_{f}^{\mathrm{q}} \mathrm{h}(\mathrm{x})=\mathrm{h}(\mathrm{x})----9$

First derivative $L_{g} \mathrm{~h}=0$ then output equation is

$\dot{y}=L_{f} \mathrm{~h}(\mathrm{x})-----10$

Second derivation

$L_{g} L_{f} \mathrm{~h}(\mathrm{x})=\frac{d\left(L_{f} h\right)}{d x} g(x)----11$

$L_{f}^{2} h(\mathrm{x})=L_{f} L_{f} h(x)---12$ 
$=\frac{d\left(L_{f} h\right)}{d x} f(x)---13$

$\vec{y}=\frac{d\left(L_{f} h\right)}{d x}[f(x)+g(x) u]---14$

$=L_{f}^{2} h(x)+L_{g} L_{f} h(x) u---15$

$L_{g} L_{f} h(x)=0----16$

$\ddot{y}=L_{f}^{2} h(x)---17$

After r times derivation if $L_{g i} L_{f}^{r i-1} h_{i}(x) \sim=0$

Condition is provided input appears in output

Then

$y_{i}^{r \mathrm{i}}=L_{f}^{\text {ri }} h_{\mathrm{i}}+\sum_{\mathrm{i}=1}^{n}\left(\mathrm{~L}_{\mathrm{gi}} L_{f}^{\text {ri }-1} h_{\mathrm{i}}\right) u_{\mathrm{i}}---18$

Applying above equation for all $\mathrm{n}$ output equations we derive

$\left[\begin{array}{c}y_{1}^{r i} \\ \overline{y_{1}} \\ \overline{y_{1}^{r n}}\end{array}\right]=\left[\begin{array}{c}L_{f}^{r i} h_{1}(x) \\ - \\ L_{f}^{r n} h_{n}(x)\end{array}\right]+E(x)\left[\begin{array}{c}u_{1} \\ = \\ u_{n n}\end{array}\right]---19$

$=\mathrm{a}(\mathrm{x})+\mathrm{E}(\mathrm{x}) \mathrm{u}$

$\mathrm{E}(\mathrm{x})$ is decoupling matrix if it is invertible and new control variable is chosen feedback transformation is obtained

$\mathrm{E}(\mathrm{x})=\left[\begin{array}{ccc}L_{g i} L_{f}^{\mathrm{i} i-1} h_{1} & \cdots & L_{g n} L_{f}^{n n-1} h_{1} \\ \vdots & \ddots & \vdots \\ L_{g 1} L_{f}^{n n-1} & \cdots & L_{g n} L_{f}^{Y n-1} h_{n}\end{array}\right]---20$

$\left[\begin{array}{c}u_{1} \\ = \\ u_{n}\end{array}\right]=-E^{-1}\left[\begin{array}{c}L_{f}^{r 1} h_{1}(x) \\ = \\ L_{f}^{g n} h_{n}(x)\end{array}\right]+E^{-1}\left[\begin{array}{c}v_{1} \\ = \\ v_{n}\end{array}\right]---21$

$\left[\begin{array}{c}y_{1}^{r 1} \\ \bar{z} \\ y_{1}^{r n n}\end{array}\right]=\left[\begin{array}{c}v_{1} \\ = \\ v_{n}\end{array}\right]---22$

Note that the above input-output relation is decoupled, in addition to being linear.

if closed loop error dynamics is considered

$\hat{y}_{\mathrm{i}}=L_{f} h_{\mathrm{i}}+\sum_{j=1}^{m}\left(L_{g j} h_{\mathrm{i}}\right) u_{j}----23$

$y_{i}^{(r i))}=\left[\begin{array}{l}V_{d c}^{s} \\ w_{m}^{s}\end{array}\right]-\cdots--24$

\subsection{Voltage Sourced Converter}

Main configuration of VSC

In many industrial applications, it is desired that the rectifiers have the following features; high-unity power factor, low input current harmonic distortion, variable dc output voltage and occasionally, reversibility. Rectifiers with diodes and thyristors cannot meet most of these requirements. However, PWM rectifiers can provide these specifications in comparison with phase-controlled rectifiers that include diodes and thyristors. The power circuit of VSC topology shown in Fig.1 is composed of six controlled switches and input L filters. Ac-side inputs are ideal three-phase symmetrical voltage source, which are filtered by inductor $\mathrm{L}$ and parasitic resistance R, then connected to three-phase rectifier consist of six insulated gate bipolar transistors (IGBTs) and diodes in reversed parallel. The output is composed of capacitance and resistance. Fig 1 shows general converter with voltage source and IGBT'S with a capacitor and resistive load. 


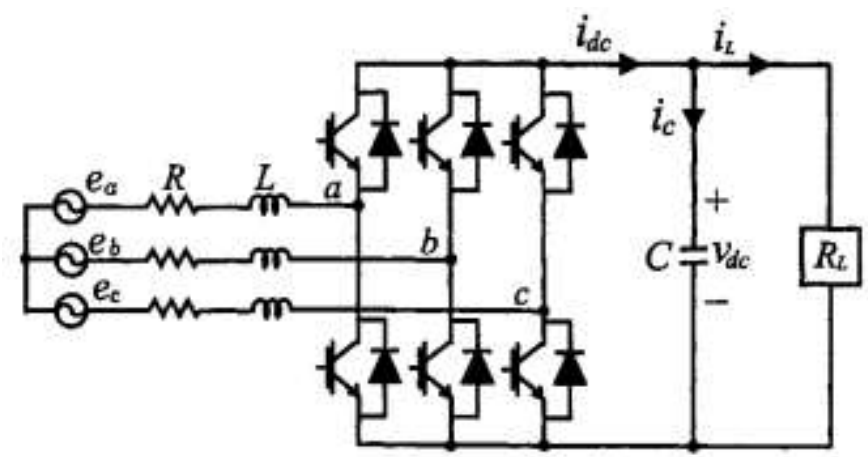

Fig1. AC/DC PWM converterpower circuit

\section{Mathematical Model Of The Vsc}

\subsection{Model of the VSC in the three-phase reference frame}

Considering state variables on the circuit of Fig.1 and applying Kirchhoff laws, model of VSC in the three-phase reference frame can be obtained, as in The model of VSC is carried out under the following assumptions.

$\square$ The power switches are ideal devices.

$\square$ All circuit elements are LTI (Linear Time Invariant)

$\square$ The input AC voltage is a balanced three-phase supply.

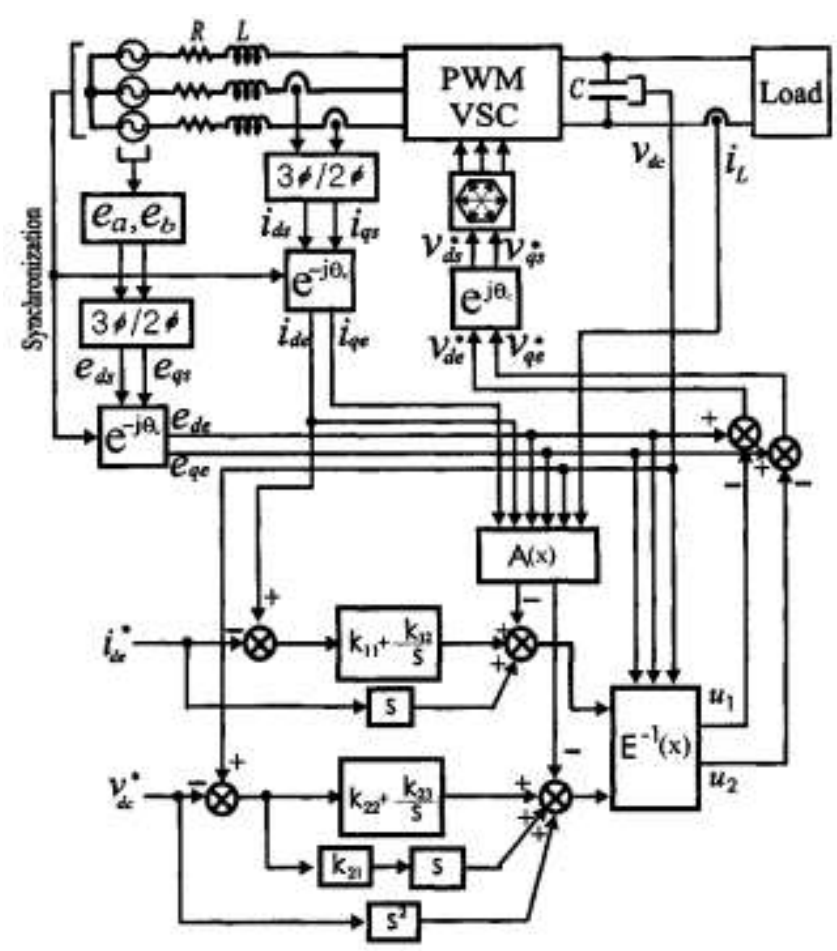

Fig2.Nonlinear control block diagram.

The above fig2.is the non linear control block of the converter circuit with d-q transformation and PI control operation.

Table 1. Converter ratings

\begin{tabular}{|l|l|}
\hline output power & $1.5 \mathrm{kVA} ;$ \\
supply voltage & $110 \mathrm{Vrms}, 60 \mathrm{~Hz} ;$ \\
input current & $7.9 \mathrm{Arms}$ \\
dc output voltage & $180 \mathrm{~V} ;$ \\
switching frequency & $3.5 \mathrm{kHz} ;$ \\
line inductor & $3.3 \mathrm{mH} ;$ \\
dc capacitor & $2350 / 660 \_F$. \\
\hline
\end{tabular}




\subsection{Spacevector Pulsewidth Modulation}

SV-PWM is actually just a modulation algorithm which translates phase voltage (phase to neutral) references, coming from the controller, into modulation times/duty-cycles to be applied to the PWM peripheral. It is a general technique for any three-phase load, although it has been developed for motor control. SV-PWM maximizes DC bus voltage exploitation and uses the "nearest" vectors, which translates into a minimization of the harmonic content. Space Vector Pulse Width Modulation (SVPWM) method has higher utilization rate of DC voltage and smaller output waveform distortion. Space vector pulse width modulation (SVPWM) is a computationally controlled PWM technique applied in industry for its efficient use of direct current voltage, low switching loss, low computational complexity, and high flexibility.Other advantages of SVPWM include a wide linear modulation range, low switching loss, easy implementation, and fewer computations due to the reduced number of sin functions. Advances in microprocessors decreased computation time further, leading SVPWM to become the preferred PWM technique. Fig3 below shows the total grid connected system.

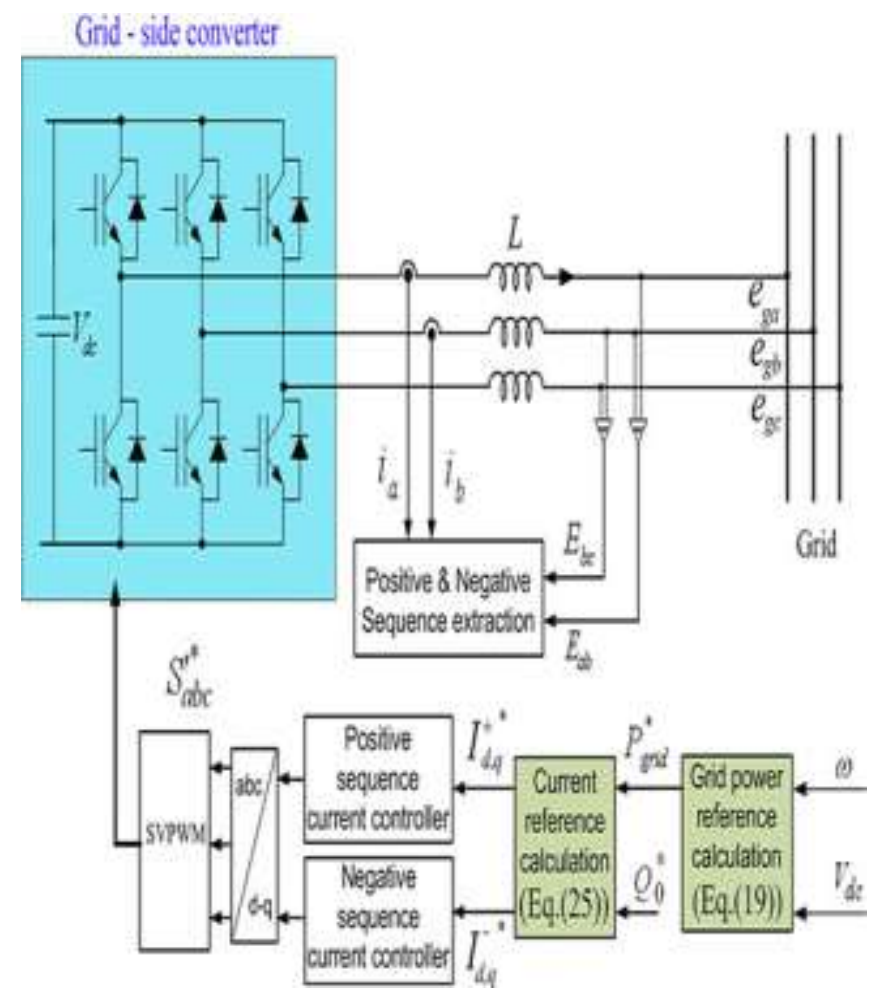

Fig3.control block diagram of grid side converter

A nonlinear relationship between the generator speed and the dc-link voltage is derived, where the dclink voltage is chosen as output. Then, by applying the feedback linearization, a linearized system is obtained and then the dc-link voltage controller can be designed by the classical linear control theory. In the meanwhile, the power of the PMSG is controlled by the GSC. The GSC dual current controllers in the positive and negativesequence reference frames are employed for grid unbalanced conditions. The validity of the control algorithm can be verified by simulation and experiment results for the PMSG wind power system.

With the exchange of the control roles of the two converters, the dc-link voltage can be controlled to be constant by increasing the generator speed during the grid voltage sag. On the other hand, a linearization technique using an input-output feedback has been applied to various areas such as the dc-link voltage control of PWM converters and the output voltage control of three-phase uninterruptible power system (UPS) inverters for the high dynamic responses. 


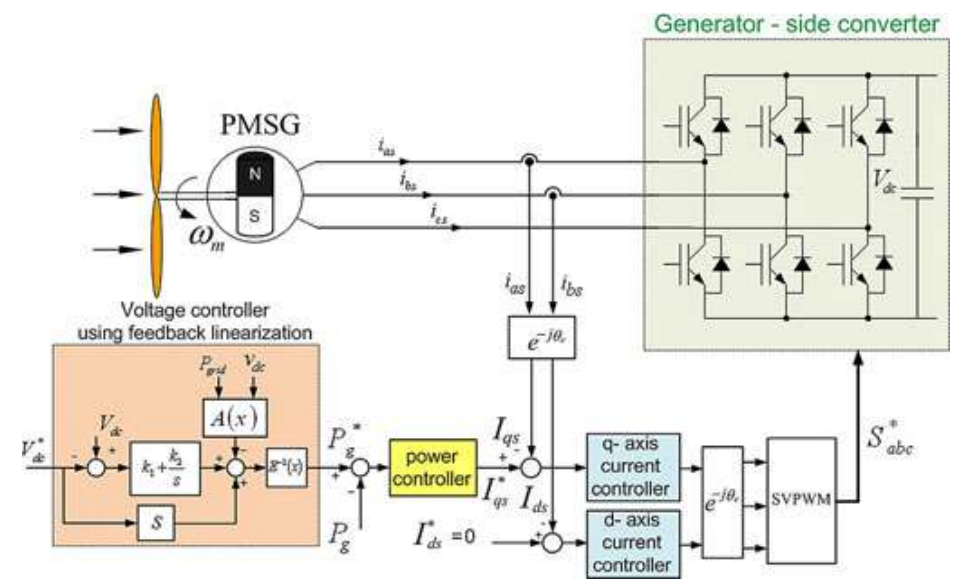

Fig4.control block diagram of generator side converter

This can be extended by using permanent magnet synchronous generator (PMSG) wind turbine system with the help of feedback linearization to control the DC link voltage as shown in fig 4. Fig5 is the total inter connected system of grid side converter as well as generator side converter which is used for future work.

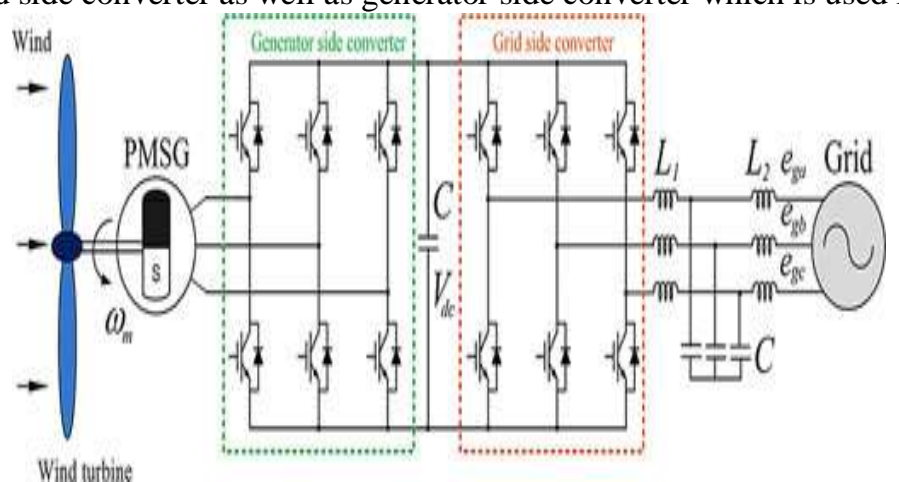

Fig5.PMSG wind power system

To consider a permanent magnet synchronous generator the figure 6 shows the wind turbine characteristics.
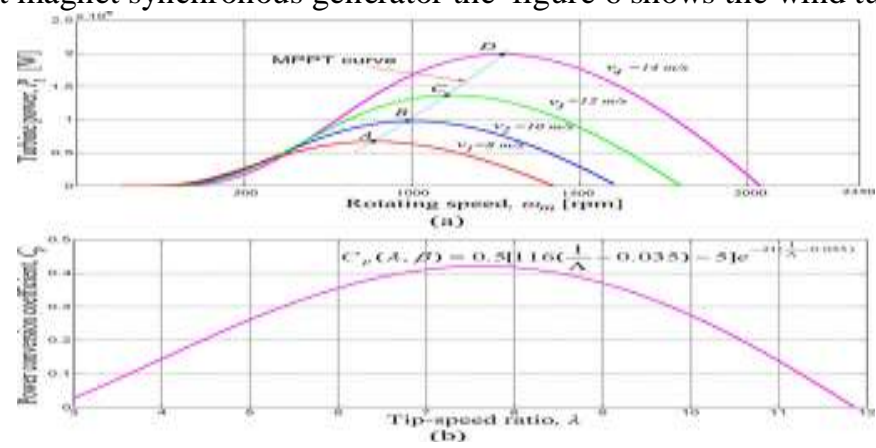

Fig6. Wind turbine characteristics (a) $\mathrm{Pt}-\omega \mathrm{m}$ curve. (b) $\mathrm{Cp}-\lambda$ curve.

Table.2 Parameters of wind turbine for simulation

\begin{tabular}{l|c}
\hline Rated power & $2[\mathrm{MW}]$ \\
Air density & $1.225\left[\mathrm{~kg} / \mathrm{m}^{3}\right]$ \\
Blade radius & $45[\mathrm{~m}]$ \\
Max. power conv. coeff. & 0.41 \\
Optimal tip-speed ratio & 8.1 \\
Rated wind speed & $13.5[\mathrm{~m} / \mathrm{s}]$ \\
\hline
\end{tabular}

\section{Simulation Results}

Now a day, Simulation has become a very powerful tool in the industrial applications as well as in academics. Simulation is one of the best ways to study the system or circuit behavior. It is now essential for an electrical engineer to understand the concept of simulation and learn its use in various applications. MATLAB is an interactive system whose basic data element is an array that does not require dimensioning. Sim Power 
Systems extends simulink with tools for modeling and simulating basic electrical circuits and detailed electrical power systems.

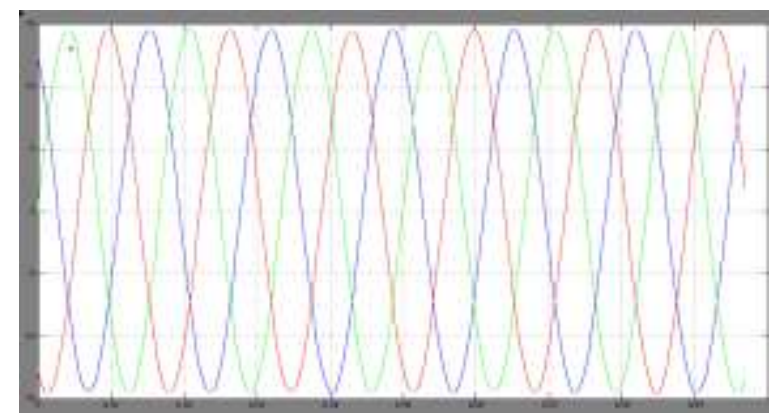

Fig7. Three phase input wave form

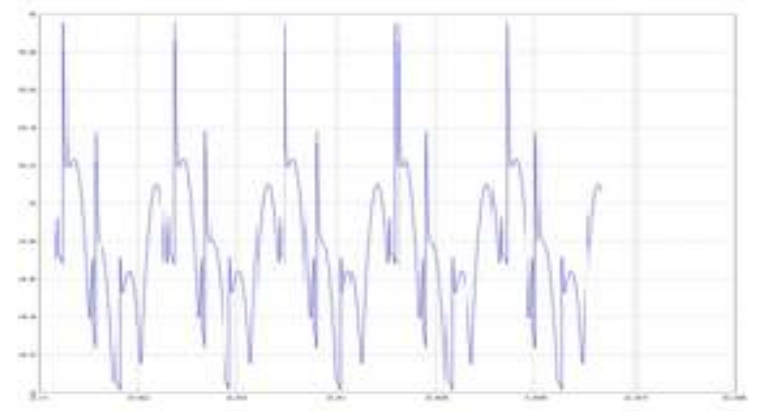

Fig 8. Harmonics in DC link voltage

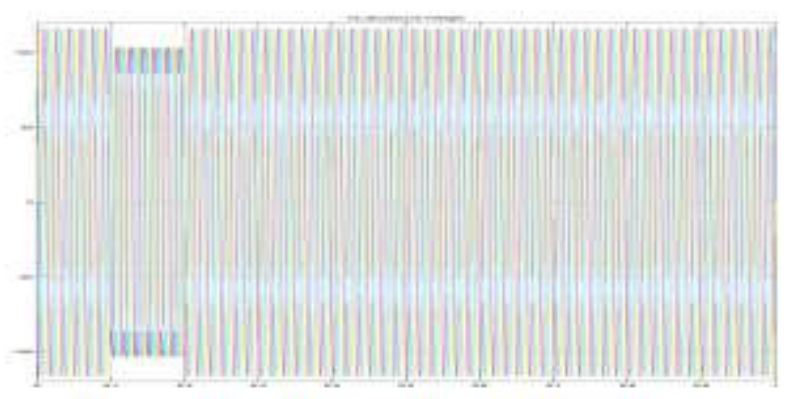

Fig9Harmonics in three phase source voltage nonlinear design

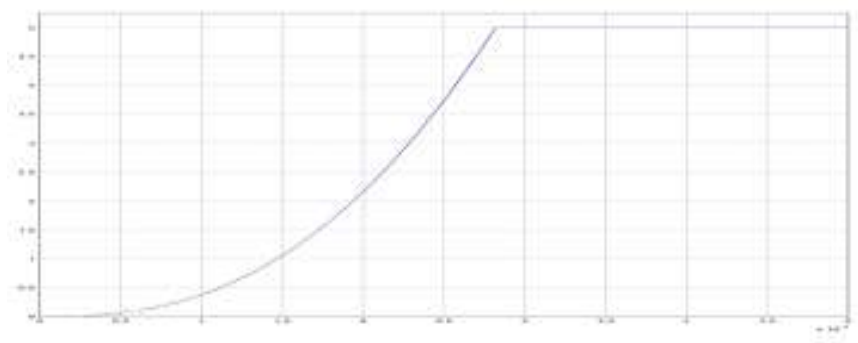

Fig10. Dc capacitor voltage

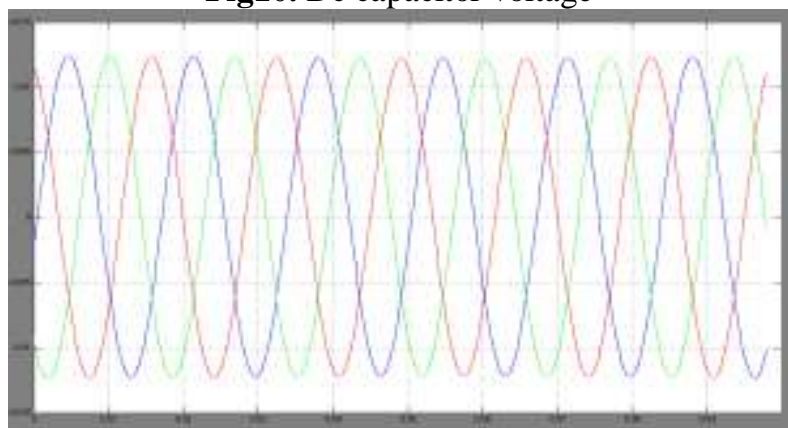

Fig11. SVPWM three phase source voltage 


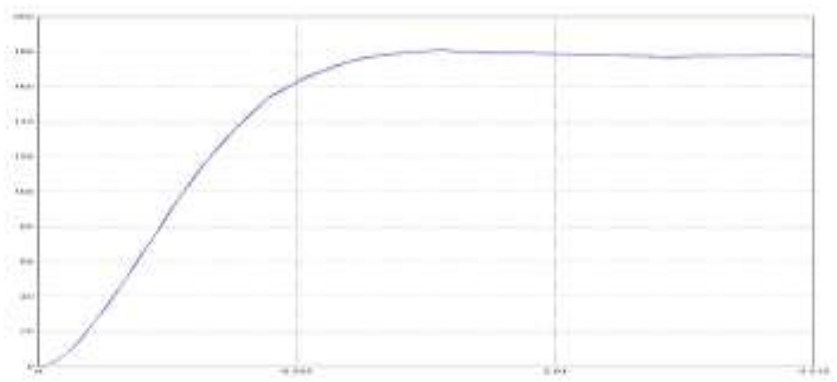

FIG 12. SVPWM DC LINK VOLTAGE

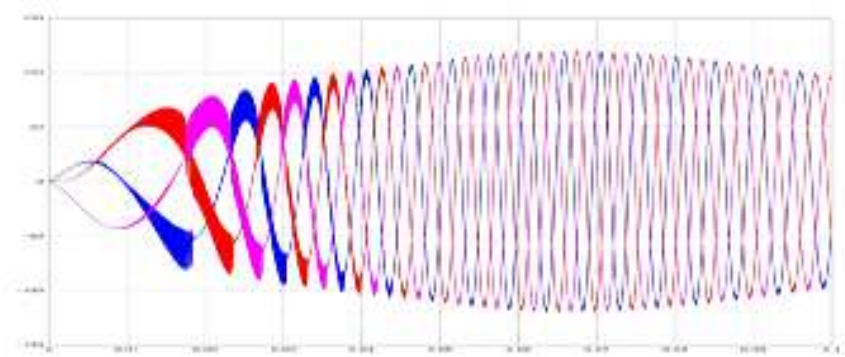

Fig.13.source voltage of SVPWM connected to wind

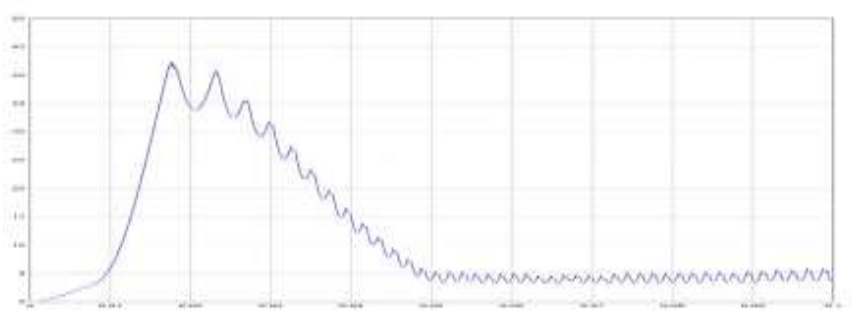

Fig.14. capacitor voltage of SVPWM wind system

\section{Conclusion}

For high-performance control of ac/dc PWM converters, a nonlinear control technique using feedback linearization was proposed. The nonlinearity of the modelled system was eliminated by the proposed nonlinear control scheme, so the linear control law was obtained with the pole placement. The control strategy is able to give higher performance in transient states such as the step change of the voltage reference and the load since the instantaneous power balance between input and output sides is introduced in system modelling and since the differential component of the load current is used in the control. Also, the coupling effect of the d-q current control was removed since the nonlinearity of the system was completely eliminated in theory. By adding integrators to the exact feedback linearization, the zero tracking errors were made, even in the presence of parameter perturbation. Since the output voltage variation for load changes is small, the dc capacitor size can be reduced remarkably without exceeding the maximum capacitor ripple current. The capacitor size can be reduced further depending on the ripple current capability.

In this method, the dc-link voltage control is performed by the generator-side converter, not by the GSC which is usually used. A new dc-link voltage controller has been designed and implemented using feedback linearization theory. The GSC controls the grid power according to the MPPT strategy. For unbalanced grid voltage conditions, the current control using a double-frame controller has been applied for the positive and negative-sequence components. The test results have shown a good dc-link voltage control performances for unbalanced grid voltage sags.

\section{References}

[1]. Ki-Hong Kim,Yoon-Cheul Jeung, Dong-Choon Lee and Heung-Geun Kim "LVRT Scheme of PSMG wind power system based on feedback linearization", IEEE Transactions on Power Electronics, vol.27,no.5,may2012.

[2]. J. Dai, D. Xu, B.Wu, and N. R. Zargari, "Unified DC-link current control for low-voltage ride-through in current-source-converterbased wind energy conversion systems," IEEE Trans. Power Electron., vol. 26, no. 1, pp. 288-297, Jan. 2011.

[3]. D.-E. Kim and D.-C. Lee, "Feedback linearization control of three-phase UPS inverter systems," IEEE Trans. Ind. Electron., vol. 57, no. 3, pp. 963-968, Mar. 2010.

[4]. G. Foo and M. F. Rahman, "Sensorless direct torque and flux-controlled IPM synchronous motor drive at very low speed without signal injection,” IEEE Trans. Power Electron., vol. 57, no. 1, pp. 395-403, Jan. 2010. 
[5]. A.Vladan Stankovic, and K. Chen, “A New Control Method for Input-Output Harmonic Elimination of the PWM Boost Rectifier under Extreme Unbalanced Oper-ating Conditions,” IEEE Transactions on Industrial Elec-tronics, Vol. 56, No. 7, 2009, pp. 24202430. Doi:10.1109/TIE.2009.2017550

[6]. X. H. Wu, S. K. Panda and J. X. Xu, "Analysis of the Instantaneous Power Flow for Three-Phase Boost Recti-fier under Unbalanced Supply Voltage Conditions," IEEE Transactions on Power Electronics, Vol. 23, No. 4, 2008, pp. 1679-1691. Doi:10.1109/TPEL.2008.925158

[7]. B. Yin, R. Oruganti, S. K. Panda and A. K. S. Bhat, "An Output-Power-Control Strategy for a Three-Phase PWM Rectifier under Unbalanced Supply Conditions,” IEEE Trans. Ind. Electron. Vol. 55, No. 5, 2008, pp. 2140-2151.

[8]. D. Roiu, R. Bojoi, L. R. Limongi and A. Tenconi, "New Stationary Frame Control Scheme for Three Phase PWM Rectifier under Unbalanced Voltage Dips Conditions ," in Proc. IEEE, 2008, pp. 1-7.

[9]. M. Liserre, R. Teodorescu and F. Blaabjerg, "Multiple Harmonics Control for Three-Phase Grid Converter Sys-tems with the Use of PI-RES Current Controller in a Ro-tating Frame," IEEE Transactions on Power Electronics, Vol. 21, No. 3, 2006 , pp. 836-841. Doi:10.1109/TPEL.2006.875566

[10]. J. R. Rodigues, J. W. Dixon, J. R. Espinoza, J. Pontt and P. Lezana, "PWM Regenerative Rectifiers: State of Art," IEEE Transactions on Industrial Electronics, Vol. 52, No. 1, 2005, pp. 5-22. Doi:10.1109/TIE.2004.841149

[11]. G.-M. Lee, D.-C. Lee, and J.-K. Seok, "Control of series active power filters compensating for source voltage unbalance and current harmonics,” IEEE Trans. Ind. Appl., vol. 51, no. 1, pp. 132-139, Feb. 2004.

[12]. B. Singh, B. N. Singh, A. Chandra, K. All-Haddad, A. Pandey and D. P. Kothari, "A Review of Three-Phase Improved Power Quality Ac-Dc Converters," IEEE Transactions on Industrial Electronics,Vol. 51, No. 3, 2004, pp. 641-660. Doi:10.1109/TIE.2004.825341

[13]. T. S. Lee, "Input-Output Linearization and Zero-Dynamics Control of Three-Phase AC/DC Volt-age-Source Converters," IEEE Transactions on Power Electronics, Vol. 18, No. 1, 2003, pp. 11-22. Doi:10.1109/TPEL.2002.807145

[14]. Y. Ye., M. Kazerani and V. H. Quintana, "Modeling, Control and Implementation of Three-Phase PWM Con-verters," IEEE Transactions on Power Electronics, Vol. 18, No. 3, pp. 857-864, 2003.

[15]. D. C. Lee, G. M. Lee and K. D. Lee, "DC-Bus Voltage Control of Three-Phase AC/DC PWM Converters Using Feedback Linearization," IEEE Transactions on Industry Applications, Vol. 36, No. 3,2000, pp. 826-833. Doi:10.1109/28.845058

[16]. H.-S. Song and K. Nam, "Dual current control scheme forPWMconverter under unbalanced input voltage conditions," IEEE Trans. Ind. Appl., vol. 46, no. 5, pp. 953-959, Oct. 1999.

[17]. H. Komurcugil and O. Kukrer, "Lyapunov-Based Control for Three-Phase PWM AC/DC Voltage-Source Convert-ers," IEEE Transactions on Power Electronics, Vol. 13, No. 5, 1998, pp. 801 - 813. Doi:10.1109/63.712278

[18]. H. C. Mao, D. Boroyevich and C. Y. Lee, "Novel Re-duced-Order Small-Signal Model of Three-Phase PWM Rectifier and Its Application in Control Design and Sys-tem Analysis," IEEE Transactions on Power Electronics, Vol. 13, No. 3, 1998 , pp. 511-521.

[19]. V. Blasko and V. Kaura, "A New Mathematical Model and Control of a Three-Phase AC-DC Voltage Source Converter," IEEE Transactions on Power Electronics, Vol. 12, No. 1, 1997, pp. 116-123.doi:10.1109/63.554176

[20]. S. Hiti and D. Boroyevich and C. Cuadros, "Small-Signal Modeling and Control of Three-Phase PWM Convert-ers,"”'in Proc. Appl. Soc. Annu. Meeting. Vol. 2, 1994, pp. 1143-1150.

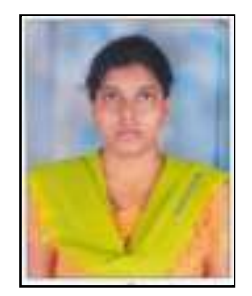

Ancha Sadhana1 received B.Tech degree in Electrical and Electronics Engineering from Nimra Women's college of Engineering and Technology in the year 2012, presently pursuing M.Tech in Power system control and Automation in Prasad V Potluri Siddhartha Institute of Technology, Vijayawada. A.P

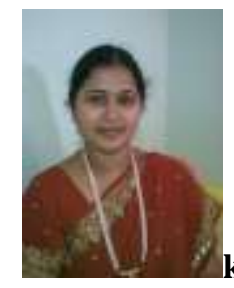

k.Bhavana ${ }^{2}$ received the B. Tech degree in Electrical and Electronics Engineering from SRKR Engineering college in 2006 and M.Tech from Vishnu engineering College and presently she is working as Assistant Professor since 2010 in Prasad V. Potluri Siddhartha Institute of Technology, Vijayawada. A.P 